\title{
Mapping Cantonese: The Pro-Cantonese Protest and Sina Weibo in Guangzhou
}

Wilfred Yang Wang ${ }^{1}$

(1)Digital Media, Independent Scholar, Melbourne, VIC, Australia

\section{Wilfred Yang Wang}

Email: wilfred.wang@connect.qut.edu.au

\begin{abstract}
This chapter explores the reproduction of Guangzhou's local identity during the pro-Cantonese protest in 2010 on Sina Weibo, one of the most popular social media platforms in China. Specifically, the chapter posits that Cantonese is one of Guangzhouers' bodily doings and Weibo is also part of the Guangzhou body. Henceforth, Cantonese was not merely the source of contention, but the local language enabled the reconfiguration of the local subjectivity through the practices of digital place remaking. By examining the collected Weibo data during the protest, it is found that Cantonese facilitated a series of cultural practices and physical doings on Weibo that enhanced the spatial mobility of the Guangzhou body during the protest. The intertwining between Cantonese and Weibo emancipated the Guangzhou's body from the cultural authorities of the Chinese state by allowing it to reproduce and reassert its locality and individuality. Cantonese, the Guangzhou city, and Weibo were co-constitutive in configuring the spatial mobility of the Guangzhou body, allowing it to be simultaneously presenting within the virtual and physical worlds and transiting between the social and cultural spaces of Guangzhou and Hong Kong. This chapter has the potential to contribute to our knowledge of digital media and society by connecting geo-lingual research with those studies of digital media culture and politics.
\end{abstract}

Keywords Cantonese - Geo-identity - Guangzhou - Sina Weibo - Spatial mobility

\section{Introduction}

One of the key policy initiatives of the Communist Party of China in the 1950s was to promote Mandarin ( putonghua), which is based on the Beijing dialect. The policy has since been enforced across major cities and as a result, local dialects are generally not permitted to be used on broadcasting media and educational institutions in China (SARFT 2005). However, Guangzhou has had a different experience, where Cantonese is used for daily communication and on local broadcasting media - an attempt to attract and retain Hong Kong's and overseas Cantonese investors during the early years of China's economic reform (Cheung 2001). Against these policy and 
historical contexts, on July 25, 2010, more than a thousand people marched on the streets of Guangzhou to protest against the provincial government's attempts to abolish Cantonese on Guangzhou television. Despite an official warning, this mass gathering was organized through Sina Weibo (microblog), one of the most popular social media services in China (J.M. 2010). Under tremendous public pressure, the provincial government withdrew the edict on Cantonese and issued official support of the preservation of the language.

This chapter explores the reproduction of Guangzhou's local identity during the pro-Cantonese protest on Weibo. Specifically, this chapter argues that Cantonese reconfigures the spatial mobility of the Guangzhou body through Weibo. "Spatial mobility" refers to a body's capacity and the degree of autonomy of its motion to travel between different social spaces, physical places, and virtual spheres. Such capacity of movement is enabled and conditioned by (1) the nature and affordances of the technologies and (2) the geographic structures that are constituted by different social flows and forces. In other words, the body's spatial mobility can be expanded or limited because of the technological advancement and the changing power relations in the society. The former relates to Boyd's ( 2010$)$ notion of the technological affordances, in particular those to do with digital media, the latter is a notion of relativity that links to the symbiotic relationships between individuals and the institutions. In order to properly develop this notion, the Cantonese language is considered as part of Guangzhouers' bodily doings and Weibo is also part of the Guangzhou body. Henceforth, Cantonese is not merely the source of contention but the local language enabled the reconfiguration of the local subjectivity through the practices of digital place remaking.

By examining the collected Weibo data during the protest, it is found that Cantonese facilitated a series of cultural practices and physical doings on Weibo that enhanced the spatial mobility of the Guangzhou body during the protest. The intertwining between Cantonese and Weibo emancipated the Guangzhou's body from the cultural authorities of the Chinese state and allowed it to reproduce and reassert its locality and individuality. Cantonese, the Guangzhou city, and Weibo were coconstitutive in configuring the spatial mobility of the Guangzhou body, allowing it to be simultaneously presenting within the virtual and physical worlds and transiting between the social and cultural spaces of Guangzhou and Hong Kong. The line of inquiry here hence emphasizes on the poetic relationship between people, place, and digital media during a political event. This chapter has the potential to contribute to our knowledge of digital media and society by connecting geolingual research with those studies of digital media culture and politics.

\section{Language, Power, and Digital Media}

This section puts forward two premises. First, I contend that since language is part of the human body (DeFrancis 1984 ) and that a living body produces itself in space and it also (re)produces that space (Lefebvre 1991), it represents and reproduces people's sense of spatiality and locality. Second, I draw on literature of digital embodiment (Farman 2012; Evans 2015) to further postulate that digital media renders new opportunities to transform the mode of transmission and form of presentation of language and, hence, reconfigures the mobility of our living bodies. Throughout the human history, language has been an important component for individuals to acquire their realms of existence (Nietzsche 1989) and to develop their senses of being and knowing with the greater world (Bucciferro 2012). Edwards ( 2009: 53) identifies three main characteristics of language: first, a language is a system, which implies rules and regularity of practice; second, "this system is an arbitrary one inasmuch as its articular units or elements have meaning only because of users' agreement a convention"; and third, language constructs community. As a primary bodily 
doing that is vocally expressed, aurally received, textually written and symbolically visualized (DeFrancis 1984), language can be seemed as one of those 'representational practices' described by Boellstorff ( 2016) that enact 'meaning.' Castells ( 2009: 55) goes further by stating that language "provides the linkage between the private and the public sphere, the past and the present." In other words, language is inherently a spatiotemporal process that "expands" living bodies horizontally across social spaces to forge interpersonal networks and connections; it also "stretches" living bodies vertically across time to experience the temporal transformations between the past and present. The common linguistic knowledge - such as the grammatical rules, syntactical structures, and expressions - carry people's shared experience and memories of a geographic place.

It is also precisely because language is a system that generates social meanings and guides everyday doings (Edwards 2009); social and cultural institutions also exploit language to protect, to rationalize, and to justify their domination and status quote. This is why Castells (2009: 52) sees language as "a system of codes" that allows the symbolic interaction "without worshipping of icons other than those merging in the communication of everyday life." Scholars have noted that nation states play a crucial role "on promoting dominant linguistic varieties as national languages and subjugating others to their subordinate status" (Gao 2012: 449). Note that the promotion of a national language is vertically imposed from the top with a clearly defined purpose to construct a (homogenized) sense of nationhood (Tan 2006) and the promotion of a dominant language generally works through the two mechanisms of standardization and exclusion (Phillipson 1992).

Standardization refers to the systemization of the rules of linguistic presentations, textual expressions, and aural verbalizations; exclusion refers to the marginalization of the variants that represents different interpretations of the language-constructed reality. In other words, the dominant language constructs a homogenous space that marginalizes or even eradicates any variants outside of its agenda and value system. It creates a proper space that transcends the relevancy of the individuality and subjectivity of the local bodies.

As a representational practice of the living bodies, language helps us to experience the physical places (everyday surroundings) and the imagined space (the nation). Language brings us into different spatial realms and acts as the agent and vehicle to articulate one's sense of being and knowing. Language is then a crucial site of power contestations by possessing the capacity to enable what Casey $(1993, \underline{1996})$ coins as "implacement": "there is no knowing or sensing a place except by being in that place, and to be in a place is to be in a position to perceive it" (1996: 18). Farman ( 2012: 40-41) further explains that embodied implacement is both informational (the sense of being) and directional (the sense of knowing) and very much a social-acquisition process that develops in relation with lived experience over time. However, with the advent of digital media, our embodied experience with the physical place is further complicated and diversified. As Farman ( 2012: 4) puts, "the uses of [mobile] technologies demonstrates an intimate relationship between the production of space and the bodies inhabiting those spaces." Embodiment is no longer a two-way interaction between the human body and physical place but since the digital media is now part of the body (Farman 2012; Evans 2015); the subtle three ways embodying process define new modes of sociality, ways of doings, and ways of being.

Since digital media is part of the human body that we experience the world with digital media (Evans 2015: 10-11), people's experience with the world will eventually involve the convergence of the digital and the physical. In citing Castells' concept of the networked society, Marolt ( 2013: 65) points out that even though the "network" is the dominant organizing mechanism in society today, individuals continue to craft identities on their own, "with one foot in their physical and the other in their virtual everyday lives." In other words, the living body's motions between the virtual and the physical become more instant and constant - even occurring simultaneously through digital media. The digital embodiment thesis, of course, relates to Boellstorff's ( $\underline{2016)}$ recent critique of the 
"derealization of the digital" in academic writings, which states that the digital virtual is one of the persistent context of social immersion. Boellstorff's conceptual distinction between the "virtual" and the "physical" is useful to analyze the body's motion and mobility afforded by social and technological transformations. Henceforth, "simultaneousness" is a concept that indicates that the body no longer needs to make a conscious choice to move between the material and virtual worlds. The act of switching on and off, connecting and disconnecting are becoming less a physical act but more a sense of existence and being. As Farman ( 2012: 49) writes, "our sensory-inscribed experiences of geographic space are always informed by the ways we represent that space." The practices of space representation and place making then would have to be conducted simultaneously across the virtual and the physical realms. This simultaneity enhanced living body's mobility across different scales and types of spatial realms.

At here, the following sections turn to China as the country presents itself as an excellent example to illustrate the potential tensions and conflicts of such a digital embodied language. This is particularly the case that language has become a key practice for the Communist Party of China to exert and prolong its power dominations. Next section then provides a brief overview of language policy in China and the pro-Cantonese protest.

\section{Tuipu, Spatial Politics and the Pro-Cantonese Protest}

According to Lefebvre ( $\underline{1991}$ ), the living body is "the space itself" and it also produces the (new) space, along with its motions (170-171). Since the previous section establishes that language is part of the body that further facilitate people's embodied experience with place and technology, it is only logical to posit that any attempt to control language is essentially an effort to control the space that generates social meaning. This is long practiced by the Chinese rulers. As Gao ( 2012) points out, since the Qin Shihuangdi (The First Emperor, 259 BC-210 BC), unifying the Chinese language has been a key concern for Chinese rulers. The current Communist Party of China government has enforced a Mandarin policy ( tuipu) throughout China. As Wang (2001: 9) wrote, the ultimate goal of tuipu policy was to make Mandarin the only spoken language in schools, broadcast media, government bodies, and public arenas across China. In 2001, an Order of the President was issued by the then-president Jiang Zemin to legislate tuipu (Chinese Government 2000) (hereafter referred to as the "language law"). The linguistic policy had such a focus because it would help in the construction of a uniform national identity for China. As stated in Article 5, Chapter I, in the language law:

The standard spoken and written Chinese language shall be used in such a way as to be conducive to the upholding of state sovereignty and national dignity, to the unification of the country and the unity of the nationalities, and to socialist material progress and ethical progress.

In order to achieve such a purpose, the language law specifically states that Mandarin shall be used as "the basic language in education and teaching in schools" (Article 10, Chapter II), and "shall be used by the broadcasting and TV stations as the basic broadcasting language" (Article 12, Chapter II). This echoes China's "Code of Professional Ethics of Radio and Television Hosts of China" issued by the State Administration of Radio, Film, and Television (SAPPRFT), where article 21 of the code requires that "broadcasting hosts shall be the role model to actively promote the popularization of Mandarin, use standard and correct form of written Chinese, and defend the integrity of the motherland's spoken and written language." 
The fact that the Communist Party of China was so keen on enforcing the tuipu policy and standardizing the Chinese language underpins the view that language carries great weight in supporting the Communist Party of China's power domination. As DeFrancis ( $\underline{1984}$ ) argues, Chinese is not a single language, but, instead, it is a collection of different linguistic variants that are spoken and used across China. Each linguistic variant represents a specific cultural expression and social imagination in relation to the particular local experience over time. It then appears that the promotion of Mandarin Chinese, one of the many variants of the Chinese language, is an attempt to construct a homogenous sense of knowing and imagination of the Chinese geography in order to construct a unified notion of nationhood (Judge 2002). Consequentially, the promotion of Mandarin as the only official language in the Chinese public realms (Wang 2001) ultimately involves the eradication of other variants of Chinese. In Nanning, for example, the capital city of Guangxi, where Cantonese has been a dominant language since the late Qing Dynasty (1644-1911), less than 30\% of the population now speaks it. This was due to the enforcement of tuipu on the city since the early 1990s, when Cantonese was prohibited in public and educational venues. The tuipu policy, therefore, aims to transcend the past and the significance of local place. Local place in China becomes, in Relph's ( 1970 ) term, "placeless," as it is increasingly being detached from its localized history and folk culture. Instead, local culture and history are increasingly being manipulated and narrated in a way that suits the interests of political and social elites (Oakes 2000). The promotion of a national language is an act to rationalize and naturalize nation states' authorities and rules over individuals (Gao 2012), who continue to display their identities and to assert the sense of existence through the regional and local linguistic varieties in conducting their everyday lives (Lai 2011).

The linguistic tension between the Chinese state and individuals is well illustrated by the proCantonese protest in Guangzhou. Public anger in Guangzhou was triggered by a legislative proposal put forth by Ji Keguang, the vice-chair of the proposal committee of the Chinese People's Political Consultative Conference (CPPCC) Guangzhou on July 5, 2010. The proposal suggested Mandarin ( putonghua) become the "principal" language for Guangzhou Television's news and current affairs programs advocating the use of Mandarin during prime time programming (Zhu and Tan 2010). This proposal was made in the backdrop of an earlier online opinion poll conducted by the CPPCC Guangzhou, showing that of the 30,000 respondents, only 20\% supported using Mandarin as Guangzhou TV's principal broadcasting language, while 80\% supported Cantonese (Xinhua 2010). As mentioned earlier in the chapter, Guangzhou had a "softer" implementation of the tuipu policy comparing to other major Chinese city for economic reason (Cheung 2001). The linguistic autonomy allowed Guangzhouers to access Hong Kong's media and popular culture, which they have learned about the ideas of liberal society, free speech, equality, and subversion (Fung and Ma 2002). In other words, Cantonese has reinforced Guangzhouers' sense of locality and cultural subjectivity, which are often deemed to be very different with the rest of China (Wang 2015). However, Guangzhou's linguistic autonomy is being undermined in recent years. According to the local Yangcheng Evening News (Anonymous 2010), some schools in Guangzhou are enforcing the Mandarin-only policy, both inside and outside the classroom, and students will be penalized for speaking Cantonese in the school yard.

The accumulated dissatisfactions against the governments' language policy related to the increasing volume and circulation of protest-related messages on Weibo despite the local authorities' intervention $(\mathrm{Li} 2010 a, \underline{b})$. On July 25, 2010, thousands of people responded to these messages and gathered at the subway exit of Jiannanxi subway station at 5:30 p.m. Local police were quick in action and the government deployed riot police to the scene. Protesters were shouting the slogan Fuck your mother! Go all out! - a battle slogan that was used by a famous Cantonese General in the Ming Dynasty (1368-1644), and singing a famous Hong Kong rock band Beyond's songs while condemning the provincial officials, especially Ji Keguang, of suppressing local culture (J.M. $\underline{2010}$ ). 
The protest ended peacefully as protesters walked away gradually at about 6:30 p.m. The provincial government also later issued a statement that denied any intentions to eradicate Cantonese and the proposal was also scrapped all together.

As the inquiry mainly concerns the role of Cantonese in enabling Guangzhou people's capacity to travel between and across different spatial realms and social spaces, the study primarily interested in those online and offline practices co-constituted by Weibo and Cantonese. Online data were collected by running a search of the protest slogan "Support Cantonese" ( Cheng Yиeyu), as the key phrase on Weibo's indigenous search engine. The keywords search was conducted with the "Time" and "Location" filers enabled. The research period was July 23-28, 2010, 2 days before and 1 day after the protest (July 25, 2010); and Guangzhou was the "location" set in order to generate entries that were only posted by people who identify themselves as living in Guangzhou. The primary aim of the analysis was not to code the data according to the content of the Weibo posts and then counting the number of a particular "key phrase/words"; instead, the analysis focuses on those online practices and bodily doings contributed to the formation of Guangzhou's local identity throughout the protest.

Since the researcher could not physically see the bodily doings and practices of Guangzhouers because the research was conducted after the protest in 2010, this information needed to be obtained through reading into the collected Weibo entries. The researcher reads through all the data at once to obtain an overall impression of the major themes and discourses. Each entry was then unpacked in detail and categorized it based on its content. The method of categorization allowed the analysis to examine each post against the immediate context it refers to. Table $\underline{1}$ shows the findings.Table 1 Data categories for the pro-Cantonese protest

\begin{tabular}{|c|c|c|}
\hline Labels & Count & Example \\
\hline \multicolumn{3}{|l|}{ Information } \\
\hline $\begin{array}{l}\text { Protest } \\
\text { information }\end{array}$ & 149 & $\begin{array}{l}\text { "Can anyone tell me if the pro-Cantonese gathering will still } \\
\text { go ahead? I heard the police have disapproved the public } \\
\text { gathering application" }\end{array}$ \\
\hline $\begin{array}{l}\text { Personal } \\
\text { plan on } \\
\text { protest day }\end{array}$ & 55 & "I will just go by the gathering location on my way home" \\
\hline $\begin{array}{l}\text { Future } \\
\text { actions } \\
\text { (second } \\
\text { protest in } \\
\text { HK) }\end{array}$ & 7 & $\begin{array}{l}\text { "We will have a second gathering to support Cantonese on } 1 \\
\text { August at Hong Kong" }\end{array}$ \\
\hline $\begin{array}{l}\text { Information } \\
\text { about } \\
\text { censorship }\end{array}$ & 16 & $\begin{array}{l}\text { "Look, Weibo and zf (government) are deleting my post! } \\
\text { Why am I not allowed to express my view?" }\end{array}$ \\
\hline Rationale & & \\
\hline
\end{tabular}




\begin{tabular}{|c|c|c|}
\hline $\begin{array}{l}\text { Cultural and } \\
\text { historical } \\
\text { uniqueness } \\
\text { of Cantonese }\end{array}$ & 38 & $\begin{array}{l}\text { "Cantonese is a much more sophisticated language with } 9 \\
\text { pitched tones while Mandarin only has } 4 \text { " }\end{array}$ \\
\hline $\begin{array}{l}\text { Linguistic } \\
\text { and identity } \\
\text { rights }\end{array}$ & 22 & $\begin{array}{l}\text { "I can endure the government misusing my tax, demolishing } \\
\text { my house, and social inequalities; but how dare they try to } \\
\text { take away my right to speak my mother tongue! I can never } \\
\text { endure that because Cantonese is who I am" }\end{array}$ \\
\hline $\begin{array}{l}\text { Seeking } \\
\text { external } \\
\text { supports }\end{array}$ & 19 & "Look, even foreigners are supporting Cantonese" \\
\hline $\begin{array}{l}\text { Alternative } \\
\text { actions }\end{array}$ & 21 & $\begin{array}{l}\text { "Maybe we can have more community activities about } \\
\text { Cantonese culture rather than having a protest" }\end{array}$ \\
\hline Slogan & 66 & "I support Cantonese forever!" \\
\hline & $n=393$ & \\
\hline
\end{tabular}

As shown in Table 1 , the data fell into three broad categories namely: Information, Rationale, and Slogan. The Information category includes entries seeking for confirmation of any news and information relating to the protest; the Rationale category includes those entries stating the reasons and rationales of the protest; the Slogan category contains those entries making an expression about the protest. By gaining an insight into these three broad categories, I was then able to further inquire the methods Guangzhou Weibo users deployed to search for protest-related information amid the state's interventions.

The inquiry also led me to identify some of the commonly used online and physical practices that enabled the circulation of this information. I pay specific attention to the use of Cantonese language and Weibo feature as either mentioned or reflected by these entries and found:

1 .

The majority of the Weibo entries were typed in Cantonese expression instead of the official Mandarin expression.

\section{2.}

More than one third of the entries collected contained visual or audio materials (such as a visual image or a video) embedded with the entry.

3.

A quarter of the Weibo entries were posted through a mobile device.

These three observations illustrate the motions of the practices and tactics Guangzhouers adopted throughout the protest. The focus on these bodily practices across the online and physical realms reveals languages as both the site of contestations and they reproduce the social and cultural spaces of Guangzhou city. The discussions to follow hence focus on the specific techno-lingual aspects of the pro-Cantonese protest in reproducing and representing the Guangzhou identity.

\section{Discussion}


The fact that Guangzhouers needed to protest for their linguistic rights reflects the deepening tensions between the nation state and individuals over the issue of cultural representation and identity formation in China. The Chinese government's attempt to control and maintain its power over the local places is evident from the data. A Weibo user $(23: 12,24 / 07 / 2013)$ uploaded a screenshot that showed the protest location “Jiangnan Xi Metro Station Exit A” (江南西地铁A出口 ) was determined to be "sensitive," and no results can be generated by online search engines for the eve of the protest. This confirms with King et al.'s (2013) observation that the primary aim of China's censorship is to prevent the mobilization of collective actions rather than to suppress dissents. In other words, the censoring mechanism work on the rationale to seize control of the local social spaces in order to restrict people's mobility to form protest networks, to allocate protest resources, and to mobilize participations.

However, as Castells ( 2009) states, since most people around the world still live and conduct their everyday lives in local places, any attempts to control and manipulate these places will face resistance from below. The subversive sentiments were reflected by the fact that the majority of the Weibo entries were typed in the Cantonese expressions rather than the official Mandarin expressions. This practice itself signifies a tactic of resistance that exists within the vision of the enemy. As de Certeau ( 1984) writes, tactics lives within the proper space created by the dominant; Cantonese also resides within the lingual-political space dominated by the Communist Party of China, yet, it challenges such power structures from within. Typing Cantonese became a shared practice among Guangzhou's Weibo users in their online communications. Cantonese became the code to protest and the language of the resistance. The use of Cantonese is particularly obvious in the protest's main slogan: "Fuck your mum! Go all out!" is in Cantonese, a battle slogan used by a famous Cantonese General in the Ming Dynasty (1368-1644). "Slogan" in this sense was not merely an outburst of one's grievance but it performs one's identity. It is worth noting that unlike Mandarin, there is no standardized format of written Cantonese, and Guangzhouers have never learned the written expression of their language in a systematic way (such as school or text book); instead, it was an ad-hoc, self-initiated social acquisition in light of the protest, an act of defense to reject the expansion of the state's power. In other words, Cantonese created a new cultural space for Guangzhouers to come together and to engage with the protest.

The re-making of the Guangzhou community eventually led to the re-mapping and re-navigation of the Guangzhou city. In doing so, Cantonese was visualized and audioized. As Yang ( 2008: 126) pointed out, "the most obvious feature of internet contention is its symbolic and discursive form." Among the 393 entries, 102 contain either visual images or videos. These visual and audio representations diversify the representation of Guangzhou's cultural uniqueness. For example, there is an image of a box containing many old Cantonese expressions and words, which are place-distinct and culturally specific. A video of "Let an old Guangzhou Doctor Teach you Cantonese," shows a middle-aged man speaking in traditional Cantonese tongue and introducing "old local saying" of medical jargons. Many of those expressions that are rarely used today have been recollected and presented on Weibo. Guangzhou's city culture and landmarks are exploited, too. An image of an animated robot, whose name is "BBQ Guangzhou," is holding different cultural products, such as a Cantonese style roast duck, a road sign of one of Guangzhou's oldest streets, and a bottle of Pearl River soy sauce. These digital representations of Cantonese and its associated culture mapped a temporal trajectory that connects the past and the present. These online visualizations of the Cantonese and the local culture express a sense of continuity. The historicizing of Cantonese as one of most ancient languages in China sets to dismiss the dominant cultural and social status of Mandarin, which was indeed a contemporary reinvention based on the Beijing dialect in 1956 (Gao 
2012). Hence, the sense of pride and local subjectivity were conveyed in relation to the spatiotemporally of Cantonese.

The re-construction of the Guangzhou place and the Guangzhou self were further sustained and reproduced through confronting with the authorities and Cantonese increased the mobility of protesters in bypassing the authorities' constraints on the one hand and enabling the Guangzhou body to transmit between the virtual and the physical worlds. In addition to foster a sense of community, Cantonese fooled the online censorship, the very system that attempts to regulate it. Cantonese expression can bypass the Mandarin-based censorship system. For example, a Weibo user (24/07/2013) spelt "police department" as gung on bou in Cantonese, instead of gong an bu in Mandarin. Another user (25/07/2013) referred to “the government” (政府) as “square tiger” (正虎); the pronunciations of the two words are identical in Cantonese but not in Mandarin. Therefore, it seems like Cantonese was crucial to produce a new site of protest, a new space that existed within the authorities' watch, to make political claim. The scope of this newly created social space was further fueled and expanded by Weibo's technical features of "Like," "Repost," and "Comment." Drawing on Boyd's (2012) insights of technological affordances, these technical features ensured the longitudinal of these posts to be archived, spread, and replicated across the public networks of Weibo as well as within Weibo users' personal networks. Weibo supported and sustained the new social space created by Cantonese to challenge and resist the government's control from within. Further still, some users (25/07/2013), for example, posted a screenshot of Hong Kong's Apple Daily's (the newspaper's website is banned in mainland China) coverage of the pro-Cantonese protest. The news report detailed the time, location, and rationale of the protest; this information is banned on Weibo and other Internet services in China but became available through screenshot images. Others (24/07/2010), on the other hand, uploaded a photo that was a screenshot from Hong Kong's Golden Forum; the image provided information about the second protest in Hong Kong. By transforming protest-related information from textual to visual, an image file evaded the "sensitive words detection" system. While screen capture is clearly a new protest tactics afforded by Weibo's technical advantages of visualization and mobility, it was Cantonese that develops the cultural connections that generate the cross-border cultural imaginations between Guangzhou and Hong Kong. It appears that Cantonese not only enabled the Guangzhou body to be simultaneously presenting across the virtual and the physical, the language also permitted the mobility of the Guangzhou body to travel between the social and cultural spaces of Hong Kong and Guangzhou. Such cross-border networks formation also redefines the Guangzhou identity through Hong Kong's liberal social values and cultures. Hong Kong's Cantonese pop music, in particular those of Beyond's, normally express the idea of freedom, liberty, and individuality (Ko 2010), became the anthems of the protest, and were shared on Weibo and sung on the street. Hong Kong's media and popular culture highlight Guangzhouers' self-perceived liberal and diverse social and political values, which contrast with the Communist Party of China's ideology of constructing a homogenous and united national identity (Wang 2015); these references to Hong Kong also reproduced and reinforce that idea that the Guangzhou body is closer to the liberal Hong Kong rather than the political center of Beijing.

These vernacular tactics illustrate that Cantonese and Weibo were both part of the Guangzhou body, which continue to redefine and shape the people's embodied experience with the city and its transformations. Yet, the technology and the language also redefined each other's capacities in delivering and re-inventing the required networks and communities to functionalize the protest. The typing of Cantonese and the visualization of subversive texts and messages, Cantonese and Weibo seem to have co-constituted new mobility for the Guangzhou body to travel between the online and the offline, to travel across Hong Kong and Guangzhou's social spaces. It appears that those 
subversive tactics were less the conscious acts and plans to facilitate a political movement; but instead, they were just part of the natural and collective social doings and cultural beings of the Guangzhou body in responding to the power expansion of the state. Resistance, in this case, was not merely about making a political claim but also about the re-making of a local subjectivity through reconfiguring the spatial mobility of the body. These highly fluid tactics coordinated what Farman ( 2012) would term as the reconfiguration of body and space through the use of digital media that new space can be created through a digitized body. Or, to draw on Boyd's ( $\underline{2010}$ ) notion of the networked public, the protest network formed during the pro-Cantonese protest was not merely as a result of Weibo's algorithmic structures and logics - these terms were too technical; instead, the networked public was forged through the co-constitution between Cantonese, the city, and Weibo as part of the Guangzhou body and part of the local everyday lives.

\section{Conclusion}

This chapter has examined the reproduction of the Guangzhou identity throughout the pro-Cantonese protest in 2010. Specifically, it seems that the co-constitution of Weibo and Cantonese reconfigured Guangzhouers spatial mobility through reproducing a series of bodily doings and online practices during the protest. By looking into the intersections and overlapping between Cantonese and Weibo, it appears that Guangzhou's Weibo users were able to be present themselves within the online and physical worlds, and move across Guangzhou and Hong Kong's social spaces simultaneously. While such enhanced spatial mobility is rendered by Weibo's technical advancement of visualization and transnationality, Cantonese also afforded the expansion and sustainability of the protest network by fooling the online censorship and the governments' intervention in bringing Guangzhouers together. This chapter has hopefully highlighted some crucial aspects other than those of the technological and the political, in advancing our knowledge of popular politics, lingual-identity reproduction and place representation in a digital era.

\section{References}

Anonymous. (2010). School enforces Mandarin policy, intergeneration discommunication (Xuexiao Yaoqiu Xuesheng Jiang Putonghua, Zusun Liang Jingbian 'Ji tong Ya jJiang. '). Available at http:// news.ycwb.com/2010-07/09/content_2571999.htm. Accessed 2 May 2013.

Boellstorff, T. (2016). For whom the ontology turns: Theorizing the digital real. Current Anthropology, 57(4), 387-407.

CrossRef

Boyd, D. (2010). Social network sites as networked publics: Affordances, dynamics, and implications. In Z. Papacharissi (Ed.), A networked self: Identity, community, and culture on social network sites (pp. 39-58). New York: Routledge. 
Bucciferro, C. (2012). For-get: Identity, media, and democracy in Chile. Lanham: University Press of America.

Casey, E. S. (1993). Getting back into place: Toward a renewed understanding of the place-world (2nd ed.). Bloomington: Indiana University Press.

Casey, E. S. (1996). How to get from space to place in a fairly short stretch of time. In S. Feld \& K. H. Basso (Eds.), Senses of place (pp. 13-52). Santa Fe: School of American Research Press.

Castells, M. (2009). The power of identity: The information age - economy, society, and culture (2nd ed.). Malden: Wiley-Blackwell.

CrossRef

Cheung, P. (2001). Guangdong under reform: Social and political trends and challenges. In J. Fitzgerald (Ed.), Rethinking China's provinces (pp. 125-152). London/New York: Routledge.

Chinese Government. (2000). Law of the People's Republic of China on the standard spoken and written Chinese language (Order of the President No. 37). Available at http://www.gov.cn/english/ laws/2005-09/19/content_64906.htm. Accessed 10 Aug 2014.

de Certeau, M. (1984). The practice of everyday life (trans: Rendall, S.). Berkeley: University of California Press.

DeFrancis, J. (1984). The Chinese language: Fact and fantasy. Honolulu: University of Hawai'i Press.

Edwards, J. (2009). Language and identity: An introduction. Cambridge, UK: Cambridge University Press.

CrossRef

Evans, L. (2015). Locative social media: Place in the digital age. Basingstoke: Palgrave Macmillan. CrossRef

Farman, J. (2012). The mobile interface of everyday life: Technology, embodiment, and culture. New York: Taylor \& Francis. 
Fung, A., \& Ma, E. (2002). Satellite modernity: Four modes of televisual imagination in the disjunctive socio-mediascape of Guangzhou. In S. H. Donald, Y. Hong, \& M. Keane (Eds.), Media in China: Consumption, content and crisis (pp. 67-79). London: RoutledgeCurzon.

Gao, X. (2012). “Cantonese is not a dialect”: Chinese netizens' defence of Cantonese as a regional lingua franca. Journal of Multilingual and Multicultural Development, 33(5), 449-464.

CrossRef

J.M. (2010). Protest in Guangzhou: The medium is the message. Available at http://www.economist. com/blogs/banyan/2010/07/protest_guangzhou. Accessed 10 June 2013.

Judge, J. (2002). Citizens or mothers of citizens? Gender and the meaning of modern Chinese citizenship. In M. Goldman \& E. J. Perry (Eds.), Changing meanings of citizenship in modern China (pp. 23-43). Cambridge: Harvard University Press.

King, G., Pan, J., \& Roberts, M. E. (2013). How censorship in China allows government criticism but silences collective expression. American Political Science Review, 107(02), 326-343.

CrossRef

Ko, Y. K. C. (2010). Why Beyond's songs are sung in social movements? Understanding Rock n Roll's authenticity and collective civic force through beyond. Cultural Studies, 21(1), article 3.

Lai, M. L. (2011). Cultural identity and language attitudes - Into the second decade of postcolonial Hong Kong. Journal of Multilingual and Multicultural Development, 32(3), 249-264.

CrossRef

Lefebvre, H. (1991). The production of space (trans: Nicholson-Smith, D.). English ed. Oxford: Blackwell Publishers.

Li, L. (2010a). Authority's attempt to abolish Cantonese has triggered 'Support Cantonese' movement from the civilian (Dangju Tuipu Feiyue Yinqi Minjian "Cheng Yueyu."). Available at http://www.rfa.org/cantonese/news/China-language-07232010103434.html?encoding=traditional. Accessed 12 June 2013. 
Li, L. (2010b). Guangzhou youths called for 'Support Cantonese' movement (Guangzhou Qingnian Faqi "Cheng Yueyy" Xingdong). Available at http://www.rfa.org/cantonese/features/hottopic/ Feature-language-07212010124730.html. Accessed 12 June 2013.

Marolt, P. (2013). Re-thinking virtual/physical boundaries. Localities, 3, 63-101.

Nietzsche, F. (1989). Friedrich Nietzsche on rhetoric and language. New York: Oxford University Press.

Oakes, T. (2000). China's provincial identities: Reviving regionalism and reinventing "Chineseness". The Journal of Asian Studies, 59(3), 667-692.

CrossRef

Phillipson, R. (1992). Linguistic imperialism (4th ed.). New York: Oxford University Press.

Relph, E. (1976). Place and placelessness. London: Pion.

SARFT. (2005). Code of professional ethics of radio and television hosts of China (Zhongguo Guangbo Dianshi Boyinyue Zhuchiren Zhiye Daode Zhunze). Available at http://www.chinasarft. gov.cn/articles/2005/02/07/20070920151122290946.html. Accessed 10 Aug 2014.

Tan, C. (2006). Change and continuity: Chinese language policy in Singapore. Language Policy, $5(1), 41-62$.

CrossRef

Wang, P. (2001). Discussing the regulations in the constitution of 'Nationwide promotion of Putonghua' (Lun Xianfa Guanyu 'Guojia Tuiguang Quanguo Tongyong de Putonghua' de Kuiding). The Journal of Beijing College of Politics and Law, 27, 9-11.

Wang, W. Y. (2015). Remaking Guangzhou: Geo-identity and place-making on Sina Weibo. Media International Australia, Incorporating Culture \& Policy, 156, 29-38.

CrossRef

Xinhua. (2010). Proposal for news in Mandarin angers Guangzhou citizens. Available at http:// news.xinhuanet.com/english2010/china/2010-07/09/c_13392543.htm. Accessed 9 May 2013. 
Yang, G. (2008). Contention in cyberspace. In K. J. O'Brien (Ed.), Popular protest in China (pp. 126-143). Cambridge: Harvard University Press.

Zhu, D., \& Tan, W. (2010). Sing Cantonese Love Cantonese (Yuechang Yueyou Ai Heku Bao Donggua). Retrieved from Nanfang.com; http://gz.oeeee.com/a/20100712/907970.html. Accessed 3 Jan 2013. 